\title{
Progress in Oral Vaccination against Tuberculosis in Its Main Wildlife Reservoir in Iberia, the Eurasian Wild Boar
}

\author{
Beatriz Beltrán-Beck, ${ }^{1}$ Cristina Ballesteros, ${ }^{1}$ Joaquín Vicente, ${ }^{1}$ \\ José de la Fuente, ${ }^{1,2}$ and Christian Gortázar ${ }^{1}$ \\ ${ }^{1}$ Instituto de Investigación de Recursos Cinegéticos, IREC (CSIC-UCLM-JCCM), Ronda de Toledo s/n, 13071 Ciudad Real, Spain \\ ${ }^{2}$ Department of Veterinary Pathobiology, Center for Veterinary Health Sciences, Oklahoma State University, Stillwater, \\ OK 74078, USA
}

Correspondence should be addressed to Christian Gortázar, christian.gortazar@uclm.es

Received 7 February 2012; Accepted 8 May 2012

Academic Editor: Jesse M. Hostetter

Copyright ( 92012 Beatriz Beltrán-Beck et al. This is an open access article distributed under the Creative Commons Attribution License, which permits unrestricted use, distribution, and reproduction in any medium, provided the original work is properly cited.

\begin{abstract}
Eurasian wild boar (Sus scrofa) is the main wildlife reservoir for tuberculosis (TB) in Iberia. This review summarizes the current knowledge on wild boar vaccination including aspects of bait design, delivery and field deployment success; wild boar response to vaccination with Bacillus Calmette-Guérin (BCG) and inactivated Mycobacterium bovis; and wild boar vaccination biosafety issues as well as prospects on future research. Oral vaccination with BCG in captive wild boar has shown to be safe with significant levels of protection against challenge with virulent $M$. bovis. An oral vaccination with a new heat-killed $M$. bovis vaccine conferred a protection similar to BCG. The study of host-pathogen interactions identified biomarkers of resistance/susceptibility to tuberculosis in wild boar such as complement component 3 (C3) and methylmalonyl coenzyme A mutase (MUT) that were used for vaccine development. Finally, specific delivery systems were developed for bait-containing vaccines to target different age groups. Ongoing research includes laboratory experiments combining live and heat-killed vaccines and the first field trial for TB control in wild boar.
\end{abstract}

\section{Introduction}

Total eradication of an infectious agent shared between wild and domestic animals is almost impossible if a native wildlife host is able to serve as a natural reservoir of the pathogen [13]. Tuberculosis (TB) is a chronic disease caused by infection with Mycobacterium bovis and closely related members of the Mycobacterium tuberculosis complex (MTC). TB affects not only cattle but also a range of other livestock, companion animals, and wild animals. Humans are also susceptible; hence control of the risks of zoonotic infection is a driver for disease control in animal hosts. As TB prevalence has been reduced in livestock, the relative epidemiological and socioeconomic importance of wildlife reservoirs has increased and there is a corresponding need for disease management strategies to reflect this effect [4].

Disease control through vaccination of wildlife reservoirs has advantages over other approaches. When dealing with disease maintenance by native wildlife, vaccinationas opposed to culling-is a nondestructive method of controlling disease that is more acceptable to the public [5, 6 ]. The primary goal of a wildlife vaccine would be to reduce the prevalence of infection in the wildlife reservoir or to change the expression of the disease and limit the rate of $M$. bovis excretion [7]. Indeed, vaccination is nowadays explored as an option for TB control in all major wildlife reservoir hosts such as the brushtail possum (Trichosurus vulpecula) in New Zealand, Eurasian badger (Meles meles) the United Kingdom and the Republic of Ireland, and white-tailed deer (Odocoileus virginianus) in the USA, among others [8].

In Mediterranean habitats of the south-western Iberian Peninsula, the abundant and widespread native Eurasian wild boar (Sus scofa) is an important driver in M. bovis epidemiology [9], thus the need for TB control in this species. Since uninfected 2-4-month-old wild boar piglets are the preferred age class for vaccination [10], an oral 
delivery system that targets piglets is needed for field application of oral tuberculosis vaccines in wild boar. After briefly introducing the role of the wild boar in tuberculosis (TB) epidemiology and the options for TB control, this review summarizes the current knowledge on wild boar vaccination including aspects of bait design, delivery, and field deployment success; wild boar response to vaccination with BCG and inactivated Mycobacterium bovis; wild boar vaccination biosafety issues as well as prospects on future research.

\section{Tuberculosis in Eurasian Wild Boar}

The Eurasian wild boar is the ancestor of the domestic pig. It is native to Eurasia and the north of Africa and has been introduced, pure or crossbred, to many other regions worldwide. TB is one of the main infections shared between wild boar and other wild and domestic animals [4]. TB has a complex epidemiology involving multiple hosts and is influenced by climate, habitat, and management factors. Consequently, the role of wild and domestic hosts in TB epidemiology varies among regions [11].

Despite the success of compulsory test and slaughter campaigns in cattle, bovine TB (bTB) is still present in the Iberian Peninsula, and the role of wildlife reservoirs is increasingly recognized $[4,11,12]$. In Mediterranean habitats of southern Portugal and south-western Spain, MTC transmission occurs among three wild ungulate species, wild boar, red deer (Cervus elaphus), as well as fallow deer (Dama dama), cattle, and to a lesser extent other domestic and wild animals such as goats, pigs, and Eurasian badgers $[4,13,14]$.

Nevertheless, there is consensus in defining the wild boar as the single most important TB reservoir host in this region [9, 13, 15-17]. Extremely high densities and high contact rates within social groups and at waterholes or focal food sources might contribute to the high TB prevalence, often over $40 \%$ prevalence $[12,13,16,18-20]$. Wild boar experience higher levels of exposure than deer [18] and are at greater infection risk as a result of feeding on tuberculous carrion [13]. Finally, wild boar are more likely than deer to push their way under fences, facilitating contact with livestock [12]. Work on TB time trends in Iberian wild boar has shown a stable prevalence with local variability, as well as an apparent expansion of the infection to new sites [21]. Moreover, wild boar TB has already been described in at least ten European countries (Bulgaria, Croatia, France, Germany, Hungary, Italy, Portugal, Slovakia, Spain, and the $\mathrm{UK})$, and evidence as wildlife reservoirs is growing beyond the peculiar high-density and intense-management systems of south-central Iberia [4].

Naturally, MTC-infected wild boar show visible lesions in over $80 \%$ of the cases and only microscopic lesions in another 9\% [22]. The distribution of lesions is generalized in two thirds of the cases, meaning that they are evident in more than one anatomic region. The mandibular lymph node $(\mathrm{mLN})$ is the most frequently affected organ while large generalized and lung lesions are more frequent among 1 to 2 year old subadults, which have the highest potential to excrete mycobacteria and can die due to the disease [22]. Prevalence increases with age, $<6$ month-old piglets showing a mean of $10 \%$ prevalence [15].

In contrast to wild boar, the role of feral pigs as MTC reservoirs is questioned [23-25]. However, domestic pigs and free-ranging Sus scrofa are MTC hosts in southwestern Spain [26], the Mediterranean islands of Corsica, Sardinia and Sicily [27-29], and the Hawaiian island of Molokai [30]. In Argentina, a wild-boar-derived M. bovis strain proved more pathogenic than the reference cattle-derived strain in a cattle challenge model [31]. Hence, the role of suids in the maintenance of MTC deserves more attention worldwide.

\section{Options for TB Control in Wild Boar}

The first requisite for any disease control in wildlife is establishing a proper monitoring scheme [32]. Then, actions towards disease control can be critically assessed. TB control in wildlife reservoir hosts can eventually be achieved by different means, including (1) the improvement of biosecurity and hygiene, (2) population control through random or selective culling or through habitat management, and (3) vaccination. Ideally, tools from all three fields should be combined in an integrated control strategy.

In this context, wildlife vaccination to reduce MTC infection prevalence emerges as a valuable alternative or complementary tool in TB control [43]. Capturing wild animals to vaccinate them individually is expensive, time consuming, and difficult [44]. Therefore, the most feasible approach to deliver vaccines to wildlife is the use of oral baits.

Oral vaccination against rabies was the first successful attempt to control a disease in wildlife through vaccination [45]. Thus, oral bait vaccination has also been considered for controlling other diseases such as classical swine fever in wild boar in Europe $[33,46]$ or TB in several wildlife hosts worldwide [47].

\section{Bait Design, Selective Delivery, and Field Deployment Success}

The effective and efficient field vaccination of wildlife requires the development of baits that are stable under field conditions, safe for target and nontarget species as well as the environment, and effective in reaching the target species [48-50]. A wide variety of baits have been developed in order to deliver pharmaceuticals to wild species. Lipid-based baits have been tested to deliver BCG vaccine against TB in wild animal species that act as reservoirs hosts such as badgers in United Kingdom and Republic of Ireland [44], possums in New Zealand [51-53], and while-tailed deer in USA [54].

For free-ranging Sus scrofa, three different baits have been developed and used for the oral delivery of vaccines and pharmaceuticals (Table 1). All of them are made with a cereal-based matrix containing a capsule or blister to deliver the vaccine or pharmaceutical. The palatable ingredients used for the bait matrix composition stimulate chewing to open the capsules contained in the baits and releasing their content inside the oral cavity [36]. 
TABLE 1: Characteristics of commercial, registered, or patented baits designed for the delivery of vaccines or pharmaceuticals to wild boar and feral pigs. Disadvantages include particularly their suitability for vaccine delivery to piglets.

\begin{tabular}{|c|c|c|c|c|c|}
\hline Bait & Shape and size & Use & Advantages & Disadvantages & References \\
\hline Riemser & $\begin{array}{l}\text { Square shape } \\
(4 \times 4 \times 1.5 \mathrm{~cm})\end{array}$ & $\begin{array}{l}\text { Delivery of vaccines } \\
\text { against classical swine } \\
\text { fever in Europe }\end{array}$ & $\begin{array}{l}\text { Resistant to } \\
\text { water and } \\
\text { moisture }\end{array}$ & $\begin{array}{c}\text { Not resistant to warm } \\
\text { temperatures } \\
\text { Not completely consumed by }<4.5 \\
\text { month-old wild boar piglets }\end{array}$ & [33-35] \\
\hline IREC, Spain & $\begin{array}{l}\text { Hemispherical shape } \\
\quad(\varnothing 3.4 \times 1.6 \mathrm{~cm} ; \\
\text { Figures } 1(\mathrm{a}) \text { and } 1(\mathrm{~b}))\end{array}$ & $\begin{array}{c}\text { Delivery of vaccines } \\
\text { against Mycobacterium } \\
\text { bovis in Spain }\end{array}$ & $\begin{array}{l}\text { Resistant to high } \\
\text { temperatures } \\
\text { Well accepted by } \\
2-4 \text { month-old } \\
\text { wild boar piglets }\end{array}$ & $\begin{array}{l}\text { Not resistant to water and } \\
\text { moisture }\end{array}$ & $\begin{array}{c}{[10,36-} \\
38]\end{array}$ \\
\hline PIGOUT & $\begin{array}{l}\text { Cylindrical shape } \\
\quad(9 \times 5 \mathrm{~cm})\end{array}$ & $\begin{array}{l}\text { Delivery of toxicants } \\
\text { or pharmaceuticals to } \\
\text { feral pigs in Australia } \\
\text { and USA }\end{array}$ & $\begin{array}{l}\text { Resistant to high } \\
\text { temperatures }\end{array}$ & $\begin{array}{l}\text { Large size would not be suitable } \\
\text { for piglets }\end{array}$ & [39-42] \\
\hline
\end{tabular}

For TB vaccination, wild boar piglets (rather than already infected adults) are the main target [10]. If BCG was used, accidental bait uptake by cattle needs to be avoided [55]. Hence, purpose-designed baits and oral delivery systems selective for piglets are needed. The three baits developed for free-ranging Sus scrofa have been found to be highly attractive and readily ingested by animals $[33,36,37,39,40]$. However, both Spanish and PIGOUT baits have been found to be not target-specific enough in those areas where other wildlife species can also have access to the baits [10, 41, 42]. No data concerning target specificity of Riemser baits has been published.

Field assessment of the proportion of target and nontarget individuals that consume baits is crucial to evaluate the success of a baiting campaign. Therefore, marking agents are incorporated into baits to enable identification of consuming individuals [56]. Iophenoxic acid ( $\alpha$-ethyl-2-hydroxy-2,4,6triiodebenzenepropanoic acid) and its derivatives have been used successfully to investigate baits and baiting strategies to deliver orally vaccines, contraceptives, and toxicants $[41,57-$ 61 ], since they bind to protein in the blood plasma and elevate the protein-bound iodine of animals which consume them. So, these markers can be detected in the serum of animals consuming IPA-marked baits for a long time after their ingestion [62]. In the case of wild boar, Ballesteros et al. [63] found that ethyl and propyl-iophenoxic acids could be detected in animal serum up to 18 months after their consumption when doses of 5 and $15 \mathrm{mg} / \mathrm{kg}$ were delivered.

Bait consumption rate and host specificity depend directly on the delivery method employed [10, 55]. To date, three delivery systems have been designed to allow free-ranging Sus scrofa access to baits while preventing bait consumption by nontarget species: the Boar-OperatedSystem [64-66], the HogHopper [67, 68], and portable selective wild boar piglet feeders of Spanish patent [37]. The BOS consists of a metal pole onto which a round perforated base is attached. A metal cone with wide rim slides up and down the pole and fully encloses the base onto which the baits are placed. This system has been tested in
United Kingdom [66] and the United States [65] showing low bait consumption by nontarget species. However, a possible disadvantage to this system is its cost [65]. The Hog-Hopper is a new box-shaped bait delivery device designed to allow feral pigs to access poison baits in the station, and to restrict other species (such as Australian native species and livestock) from taking bait. The door of the device is easily raised by feral pigs allowing them to feed on bait, but it excludes nontarget species that lack the physical attributes to lift the sliding door. Small rodents are also unable to access baits. The device has the added benefit of preventing bait from being exposed to rain, thereby preventing bait degradation $[67,68]$. Selective feeders were used by Ballesteros et al. [37] in order to reduce bait consumption by nontarget species in southern Spain. These triangular-shaped feeders (side $=1 \mathrm{~m})$ consist of a $1-\mathrm{cm}-\varnothing$ metal-grid cage with an opening (15-cm wide) to allow only access of young wild boar (Figure 1(c)). A green mesh that provides shade covers the cage (Figure $1(\mathrm{~d})$ ). Although this system was found to be highly selective for wild boar piglets [10], occasionally small animals such as badgers can enter inside the feeders and have access to the baits [37].

The success of vaccination programs is also determined by the timing of bait delivery. For example, early summer would be the best timing for $\mathrm{TB}$ vaccine bait delivery to wild boar piglets in south-central Spain [10]. In addition, bait consumption by wild boar or feral pigs is better if the prebaiting period lasts longer (e.g., feeding corn weekly for three weeks) so that animals get accustomed to feed in the place where baits will be delivered $[37,69,70]$. Other factors such as baiting and/or free-ranging Sus scrofa densities can affect bait consumption by target species [37]. Ballesteros et al. [37] found marked-bait consumption by up to $73 \%$ wild boar piglets at a bait density of 30 baits $/ \mathrm{km}^{2}$ and using one piglet feeder per $2 \mathrm{~km}^{2}$. These baiting densities were lower than those used in previous studies in other countries (e.g., 68 to 489 baits $/ \mathrm{km}^{2}$ [41, 57]. Therefore, in future TB vaccination experiments, it would be desirable to use higher 


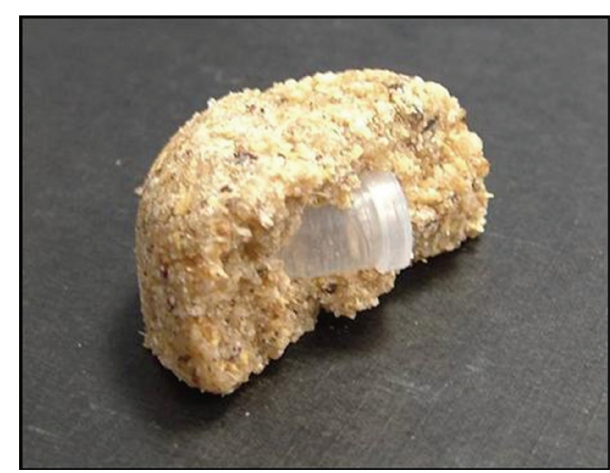

(a)

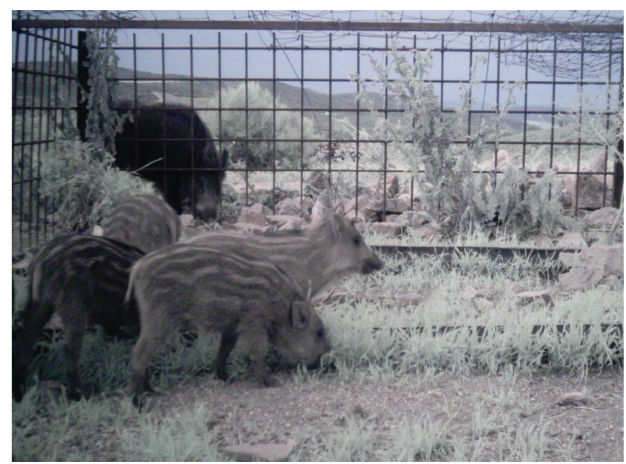

(c)

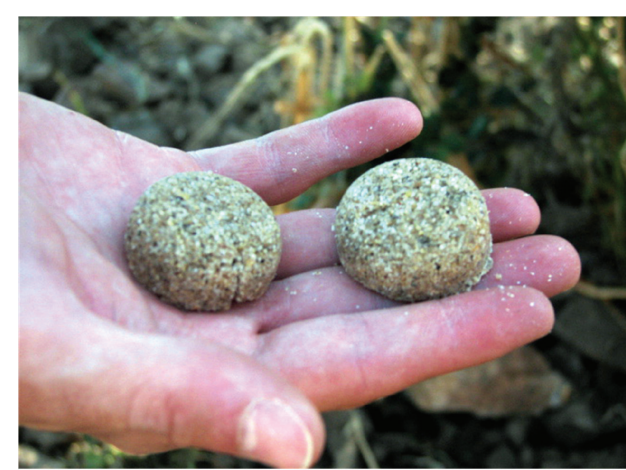

(b)

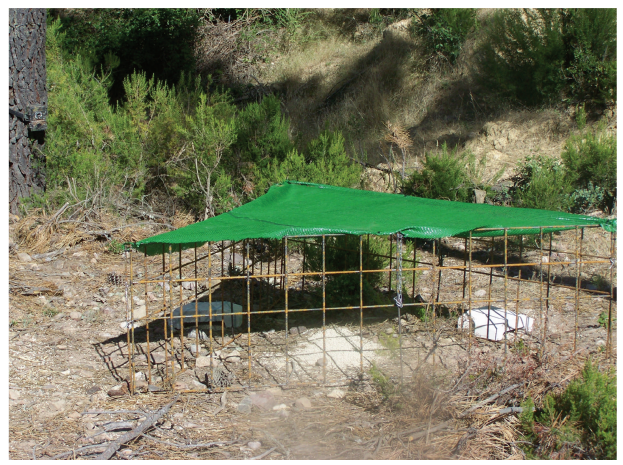

(d)

Figure 1: (a) and (b) Baits developed to deliver vaccines to wild boar in Spain. They are composed of piglet feed, paraffin, sucrose and cinnamon-truffle powder attractant. (c) Wild boar piglets consuming baits inside selective feeders. (d) Portable selective feeder used to deliver baits to young wild boar.

baiting densities to target a higher percentage of the wild boar population.

\section{Tuberculosis Vaccines in Wildlife}

Live vaccines are believed to confer more protection against mycobacterial infections than killed vaccines [71]. This is the case of the attenuated live strain of M. bovis BCG [72], which is currently the only vaccine approved for vaccination of humans against TB [73, 74]. Since 1921, BCG has been used worldwide and reports of adverse reactions arising from the use of this vaccine have been relatively uncommon [75]. Also, BCG is the most widely used vaccine for TB control in wildlife reservoirs. Experiments in controlled environments have been carried out in several host species such as badgers [76], brushtail possums [77], Cape buffalo (Syncerus caffer) [78], white-tailed deer [54, 79], wild boar [38], and ferrets (Mustela furo) [80]. In addition, recent reports on field vaccination of badgers in the UK [81] and possums in New Zealand [53] encourage the use of BCG for TB control in wildlife. Additionally, due to its long and widespread use in different species, licensing BCG for field use in wild animals is easier than licensing a newly developed vaccine $[81,82]$.

However, the use of BCG has some disadvantages, including (1) its variable efficacy in humans and cattle due to differences among BCG vaccine strains, trial methodology, and prior host sensitization to a variety of environmental mycobacteria [71, 83-87], (2) the possibility to cause disease or to infect nontarget individuals and cause interference with TB diagnosis [88-92], and (3) its limited half life in the environment and during vaccine preparation, shipment, or storage [93].

The use of killed vaccines would eliminate the risk of causing TB and should limit the likelihood of diagnostic interference and make field vaccination protocols cheaper. Several authors have found experimental evidence indicating that nonviable bacilli are able to produce some degree of protection to TB in guinea pigs [94-99], mice [100-103] and dogs [104]. In wildlife, only limited information exists regarding inactivated vaccines. Experiments with inactivated vaccines have been conducted in deer, brushtail possums, and recently in wild boar [105-107]. Deer were vaccinated with two doses of heat-killed BCG $\left(5 \times 10^{7} \mathrm{cfu}\right)$ in an oil adjuvant finding no protection against experimental challenge with virulent $M$. bovis [105]. In brushtail possums, the heat-inactivated $M$. vaccae was used to improve the effectiveness of live BCG to protect against bTB [106]. Recently, heat-inactivated $M$. bovis was found to confer protection against TB similar to BCG to wild boar [107]. 


\section{Wild Boar Response to BCG Vaccination}

The first results about wild boar response to BCG vaccination were documented in 2009, after vaccinating seven animals by the intramuscular route [108]. Later, a subsequent study by Ballesteros et al. [38] analyzed wild boar responses to oral BCG vaccination and challenge with a $M$. bovis field strain. Purpose-designed oral baits were used for the experiment [36]. The oropharyngeal route was found appropriate for wild boar experimental infection since lesions recorded resembled those of natural mycobacterial infections [109]. This research allowed defining the infection model and a lesion scoring system for wild boar TB [38], while further experiments increased the information on wild boar response to BCG vaccination [107].

In captive wild boar, BCG has shown significant levels of protection against challenge with a virulent $M$. bovis field strain. Culture scores and lesion scores of orally BCGvaccinated wild boar were consistently lower in vaccinated than in control nonvaccinated animals $[38,107]$. In addition, the reduction of the lesion and culture scores in the thoracic organs has been between $67 \%$ and $90 \%$ as compared to unvaccinated controls [107]. Vaccinated wild boar exposed to low-or-medium doses of $M$. bovis $\left(10^{2} \mathrm{cfu}\right.$ or $\left.10^{4} \mathrm{cfu}\right)$ by the oropharyngeal route generally remain either uninfected or develop only limited lesions [38].

Antibody responses of wild boar against M. bovis have been detected reliably with specific serologic tests [21, $110,111]$. This enzyme-linked immunosorbent assay uses M. bovis purified protein derivative (bPPD ELISA test). Antibodies to bPPD increase only slightly and late after challenge and correlate with the total lesion scores of BCG vaccinated and $M$. bovis challenged wild boar [107]. Additionally, an innovative dual-path platform test (DPP test) using MPB83 and CFP10/ESAT-6 antigens has also been used to monitor antibody production in vaccination experiments in captive wild boar [107, 111]. Also, IFNgamma production in response to bPPD has been detected in both BCG vaccinated and unvaccinated wild boar after $M$. bovis challenge [107].

\section{Wild Boar Response to Vaccination with Heat-Inactivated $M$. bovis}

Recently, a heat-killed M. bovis vaccine for oral and parenteral use was developed and tested in wild boar [107]. Each oral dose contained $6 \times 10^{6}$ bacteria in $2 \mathrm{~mL}$ of PBS, and each parenteral dose contained the same number of bacteria in $1 \mathrm{~mL}$ Montanide ISA $50 \mathrm{~V}$ (Seppic, Castres, France).

The first study incorporating this new inactivated vaccine showed that oral or parenteral vaccination with heatinactivated $M$. bovis conferred a similar protection after challenge when compared to oral vaccination with BCG, and that the response of wild boar to both vaccines was similar. Although a high challenge dose was used $\left(10^{6} \mathrm{cfu}\right)$, this vaccination protocol reduced the number and severity of lesions and the infection burden, particularly in the thoracic region [107].
The dynamics of antibody production, IFN-gamma response, and gene expression were similar in oral BCGand inactivated $M$. bovis-vaccinated animals. Wild boar parenterally vaccinated with the inactivated vaccine responded to the MPB83 antigen but not to bPPD immediately after vaccination, suggesting potential use of these ELISAs to distinguish between parenterally vaccinated and exposed wild boar [107].

\section{Wild Boar-Pathogen Interactions and Protection against TB}

The study of host-pathogen interactions allowed identifying biomarkers of resistance/susceptibility to tuberculosis in wild boar and using these biomarkers for vaccine development $[63,107,108,112-115]$. The expressions of some of these genes such as complement component 3 (C3) and methylmalonyl coenzyme A mutase (MUT) were shown to correlate with resistance to natural $M$. bovis infection and protection against $M$. bovis challenge in BCG-vaccinated wild boar $[9,38,107,108,116]$. In these experiments, C3 and/or MUT mRNA levels were higher in nontuberculous than in tuberculous adult wild boar naturally exposed to mycobacterial infection, decreased after $M$. bovis infection and increased with BCG vaccination, with higher mRNA levels in protected animals $[9,38,107,108,113,114,116$, 117]. Additionally, MUT may be genetically associated with resistance to tuberculosis in wild boar $[113,116,117]$.

The mechanisms by which C3 and MUT expression contributes to resistance to mycobacterial infection remain unknown. The complement system has been shown to be involved in mycobacterial pathogenesis and $M$. tuberculosis activates the alternative pathway of complement and binds C3 protein, resulting in enhanced phagocytosis by complement receptors (CR3) on human alveolar macrophages [118, 119]. A similar mechanism may occur with $M$. bovis in which C3 opsonophagocytosis of mycobacteria by macrophages may result in the inhibition of host bactericidal responses and pathogen survival [118]. Consequently, higher levels of C3 in wild boar may allow increased binding of C3 to CR3 to promote phagocytosis and effective killing of bacteria, while interfering with CR3-mediated opsonic and nonopsonic phagocytosis of mycobacteria [114]. For MUT, a hypothesis was recently discussed to suggest that host genetically defined higher MUT expression levels result in lower serum cholesterol concentration and tissue deposits that increase the protective immune response to M. bovis, thus resulting in resistance to tuberculosis and better response to BCG vaccination [117].

The mechanism of protection from BCG vaccination involves a reduction of the haematogenous spread of mycobacteria from the site of primary infection. It protects against the acute manifestations of the disease, and reduces the lifelong risk of endogenous reactivation and dissemination associated with foci acquired from prior infection [120].

It is tempting to speculate that BCG protection in wild boar would involve distinct systemic and mucosal populations of effector memory $\mathrm{T}$ cells. Immune genes with 
significant overexpression in nontuberculous than in tuberculous adult wild boar naturally exposed to mycobacterial infection include RANTES (aka Chemokine (C-C motif) ligand 5; CCL5), IFN-gamma, and IL4 [108]. The mRNA levels of these genes also increased after parenteral and oral BCG vaccination of wild boar $[38,108]$, thus suggesting that IFN-gamma and activated RANTES-secreting CD8 (+) and/or CD4 (+) T lymphocytes may be key players in BCGinduced protective response in wild boar. However, although it is generally recognized that humoral immunity is not important for the control of tuberculosis [121], IL4-induced antibody response against $M$. bovis may be important for tuberculosis control in wild boar. IL4 overexpression in nontuberculous and BCG-vaccinated wild boar suggests that antibodies against mycobacterial proteins may be used for disease surveillance and treatment monitoring in this species $[21,107,110,111]$ and underline the existence of hostspecific responses to mycobacterial infection [122] as the increase in IL4 levels correlates with disease severity in humans [123] but not in wild boar.

Inactivated vaccines stimulate specific $\mathrm{CD} 4(+)$ cell populations that recognize the antigen versus a live vaccine that stimulates many $\mathrm{T}$ cell populations simultaneously. While antibody and IFN-gamma responses increased after vaccination in parentally BCG-vaccinated wild boar, in orally BCG and inactivated $M$. bovis vaccinated wild boar, only MUT mRNA levels correlated with protection [107]. These results are difficult to explain before further experiments help to characterize the mechanism by which vaccination with the inactivated vaccine protects against tuberculosis in wild boar. Taken together, these results suggest different protective mechanisms between parenteral and oral inactivated mycobacterial vaccines and, at least for MUT, expression levels could be a marker of protection against tuberculosis and may be used to characterize host response to BCG vaccination in wild boar.

\section{Wild Boar Vaccination Biosafety Issues}

Four main biosafety issues must be considered before delivery of oral baits containing live vaccines such as BCG to wild boar: (1) potential effects of high vaccine doses (e.g. ten times the normal dose) on wild boar health; (2) potential survival of $M$. bovis BCG in vaccinated wild boar; (3) potential excretion of M. bovis BCG by vaccinated wild boar; (4) vaccine-containing bait uptake by nontarget species, particularly by cattle.

Regarding point (1), it is highly important to determine that high doses of vaccine do not affect the animal's health since it is likely that few individuals can gain access to a high number of baits during field vaccination campaigns. In the case of wild boar, no adverse effects that can be attributed to the vaccine have been detected in vaccinated individuals $[38,107,108]$. Moreover, wild boar treated with high vaccine doses of up to $3.0 \times 10^{6} \mathrm{cfu}$ did not show any adverse effect after BCG administration [38].

Concerning point (2), M. bovis BCG has never been isolated from tissues of vaccinated wild boar, despite the occasionally high doses used (the authors, unpublished information). However, in other species, such as brushtail possum and deer, BCG was isolated in tissues of oral BCG vaccinated animals after necropsy [124, 125].

Regarding point (3), the potential of faeces from vaccinated wild boar to lead to the accidental exposure of non-target species to BCG, shedding of BCG following bait ingestion has been tested under laboratory conditions over a period of seven days post vaccination. The analyses yielded no BCG isolates (unpublished data). In other TB hosts, BCG is detected in faeces only for a short period of time after ingestion $[52,125]$.

Finally, point (4), it is necessary to consider the possibility of bait consumption by nontarget species. Oral baits developed by Ballesteros et al. [36] were found highly palatable to both wild and domestic animals [55]. This fact could have negative effects in areas where cattle and wild reservoirs coexist since accidental consumption of BCG-containing baits by cattle could interfere in the TB test and slaughter campaigns. However, this risk can be reduced by using deployment strategies that assure that only target species gain access to bait such as selective feeders [10,37]. Moreover, the scheduled preliminary field experiments are taking place in sites without cattle [37]. In addition, the research towards the development of BCG-specific blood tests for cattle, and the relatively short duration of BCG-induced reactivity in livestock contribute to limit the concerns [126].

Further information regarding BCG biosafety is needed to satisfy regulatory and licensing requirements for release of oral bait vaccines to wildlife $[82,125]$. Therefore, new laboratory experiments will be conducted in order to assess the potential oral or nasal excretion of BCG by vaccinated wild boar. In addition, cattle will be exposed to BCGcontaining baits under controlled conditions to assess the likeliness of developing a positive skin test. Other important information regarding biosafety will be derived from the first controlled field experiments starting soon in Southern Spain. Furthermore, the recent development of an inactivated $M$. bovis vaccine would significantly reduce the safety issues, since no viable organisms are used [107].

\section{Conclusions and Future Research Directions}

During the last decade, research on TB epidemiology and oral vaccine development and characterization in wild boar allowed considering oral vaccination among available TB control tools. The continued applied and basic research on integrated TB control at the wildlife-livestock interface will hopefully yield even more significant advances in the future.

Future research on TB vaccination in wild boar will include both new controlled laboratory and field experiments (Figure 2). Results obtained in experiments comparing the efficacy of inactivated $M$. bovis and BCG vaccines encourage testing combinations of these vaccine preparations. The characterization of the immune mechanisms that support protection against tuberculosis after vaccination with BCG and inactivated vaccines are essential to advance in the development of new improved vaccines and/or vaccination schemes. 


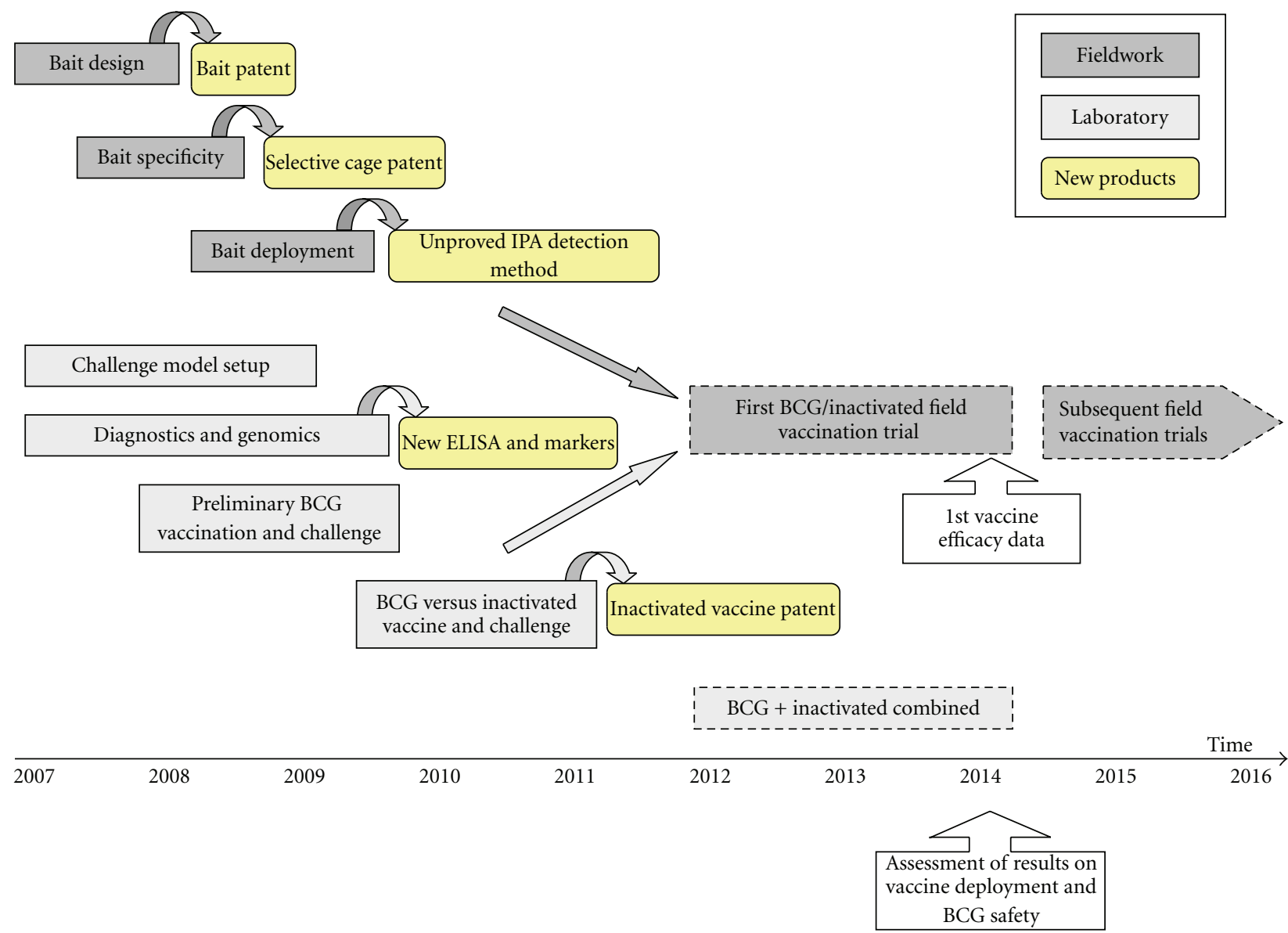

FIGURE 2: Flowchart of the laboratory and field research and key results towards oral vaccination of Eurasian wild boar against Mycobacterium bovis. Dashed boxes indicate future experiments.

A controlled and replicated experimental oral vaccination trial will start soon in southern Spain. The goals of this first field trial are assessing the response of wild boar to oral BCG and heat-killed $M$. bovis vaccination under field conditions, gathering information on safety aspects and analyzing the cost-effectiveness of vaccination for $\mathrm{TB}$ control in wild boar. This includes modeling the outcome of vaccination as compared to population control.

Regarding models, preliminary data gathered from individual-based models suggest that vaccinating piglets over a long-term period has the potential to successfully eradicate bTB from wild boar reservoirs in southern Spain. Further research into the transmission rates between bTB hosts and the efficacy of the vaccine itself, but also on the cost-effectiveness of wild boar vaccination as compared to population control (and their combinations) will add important reinforcements to these initial findings.

\section{Acknowledgments}

This study was supported by a Plan Nacional AGL201130041 grant from Ministerio de Economía y Competitividad and the EU FP7 Grant TB-STEP 212414.

\section{References}

[1] C. Gortázar, E. Ferroglio, U. Höfle, K. Frölich, and J. Vicente, "Diseases shared between wildlife and livestock: a European perspective," European Journal of Wildlife Research, vol. 53, no. 4, pp. 241-256, 2007.

[2] L. M. O'Reilly and C. J. Daborn, "The epidemiology of Mycobacterium bovis infections in animals and man: a review," Tubercle and Lung Disease, vol. 76, no. 1, pp. 1-46, 1995.

[3] D. T. Haydon, S. Cleaveland, L. H. Taylor, and M. K. Laurenson, "Identifying reservoirs of infection: a conceptual and practical challenge," Emerging Infectious Diseases, vol. 8, no. 12, pp. 1468-1473, 2002.

[4] C. Gortázar, R. J. Delahay, R. A. McDonald et al., "The status of tuberculosis in European wild mammals," Mammal Review, vol. 42, no. 3, pp. 193-206, 2012.

[5] V. Kaden, A. Hänel, C. Renner, and K. Gossger, "Oral immunisation of wild boar against classical swine fever in Baden-Württemberg: development of the seroprevalences based on the hunting bag," European Journal of Wildlife Research, vol. 51, no. 2, pp. 101-107, 2005.

[6] M. L. Cross and F. Aldwell, "Oral vaccination against bovine tuberculosis with Mycobacterium bovis BCG," Expert Review of Vaccines, vol. 6, no. 3, pp. 323-331, 2007. 
[7] L. A. L. Corner, D. Murphy, and E. Gormley, "Mycobacterium bovis infection in the Eurasian Badger (Meles meles): the disease, pathogenesis, epidemiology and control," Journal of Comparative Pathology, vol. 144, no. 1, pp. 1-24, 2011.

[8] M. V. Palmer, T. C. Thacker, W. R. Waters et al., "Mycobacterium bovis: a model pathogen at the interface of domestic livestock, wildlife, and humans," Veterinary Medicine International. In press.

[9] V. Naranjo, C. Gortazar, J. Vicente, and J. de la Fuente, "Evidence of the role of European wild boar as a reservoir of Mycobacterium tuberculosis complex," Veterinary Microbiology, vol. 127, no. 1-2, pp. 1-9, 2008.

[10] C. Ballesteros, R. Carrasco-García, J. Vicente et al., "Selective piglet feeders improve age-related bait specificity and uptake rate in overabundant Eurasian wild boar populations," Wildlife Research, vol. 36, no. 3, pp. 203-212, 2009.

[11] C. Gortazar, J. Vicente, M. Boadella et al., "Progress in the control of bovine tuberculosis in Spanish wildlife," Veterinary Microbiology, vol. 151, no. 1-2, pp. 170-178, 2011.

[12] M. Vieira-Pinto, J. Alberto, J. Aranha et al., "Combined evaluation of bovine tuberculosis in wild boar (Sus scrofa) and red deer (Cervus elaphus) from Central-East Portugal," European Journal of Wildlife Research, vol. 57, no. 6, pp. 11891201, 2011.

[13] C. Gortázar, M. J. Torres, J. Vicente et al., "Bovine tuberculosis in Doñana Biosphere Reserve: the role of wild ungulates as disease reservoirs in the last Iberian lynx strongholds," PLoS ONE, vol. 3, no. 7, Article ID e2776, 2008.

[14] R. Sobrino, M. P. Martín-Hernando, J. Vicente, C. Gortázar, O. Aurtenetxe, and J. M. Garrido, "Bovine tuberculosis in a badger (Meles meles) in Spain," Veterinary Record, vol. 163, no. 5, pp. 159-160, 2008.

[15] J. Vicente, U. Höfle, J. M. Garrido et al., "Wild boar and red deer display high prevalences of tuberculosis-like lesions in Spain," Veterinary Research, vol. 37, no. 1, pp. 107-119, 2006.

[16] N. Santos, M. Correla-Neves, S. Ghebremichael, G. Källenius, S. B. Svenson, and V. Almeida, "Epidemiology of Mycobacterium bovis infection in wild boar (Sus scrofa) from Portugal," Journal of Wildlife Diseases, vol. 45, no. 4, pp. 1048-1061, 2009.

[17] A. Parra, A. García, N. F. Inglis et al., "An epidemiological evaluation of Mycobacterium bovis infections in wild game animals of the Spanish Mediterranean ecosystem," Research in Veterinary Science, vol. 80, no. 2, pp. 140-146, 2006.

[18] J. Vicente, U. Höfle, J. M. Garrido et al., "Risk factors associated with the prevalence of tuberculosis-like lesions in fenced wild boar and red deer in south central Spain," Veterinary Research, vol. 38, no. 3, pp. 451-464, 2007.

[19] C. Gortazar, M. J. Torres, P. Acevedo et al., "Fine-tuning the space, time, and host distribution of mycobacteria in wildlife," BMC Microbiology, vol. 11, Article ID 27, 2011.

[20] G. Mentaberre, E. Serrano, R. Velarde et al., "Absence of TB in Iberian ibex (Capra pyrenaica) in a high-risk area," Veterinary Record, vol. 166, no. 22, p. 700, 2010.

[21] M. Boadella, P. Acevedo, J. Vicente et al., "Spatio-temporal trends of iberian wild boar contact with Mycobacterium tuberculosis complex detected by ELISA," EcoHealth, vol. 8, no. 4, pp. 478-484, 2011.

[22] M. P. Martín-Hernando, U. Höfle, J. Vicente et al., "Lesions associated with Mycobacterium tuberculosis complex infection in the European wild boar," Tuberculosis, vol. 87, no. 4, pp. 360-367, 2007.

[23] L. A. Corner, R. H. Barrett, A. W. Lepper, V. Lewis, and C. W. Pearson, "A survey of mycobacteriosis of feral pigs in the
Northern Territory," Australian Veterinary Journal, vol. 57, no. 12 , pp. 537-542, 1981.

[24] G. Nugent, "Maintenance, spillover and spillback transmission of bovine tuberculosis in multi-host wildlife complexes: a New Zealand case study," Veterinary Microbiology, vol. 151, no. 1-2, pp. 34-42, 2011.

[25] G. Nugent, J. Whitford, I. J. Yockney, and M. L. Cross, "Reduced spillover transmission of Mycobacterium bovis to feral pigs (Sus scofa) following population control of brushtail possums (Trichosurus vulpecula)," Epidemiology and Infection, vol. 140, no. 6, pp. 1036-1047, 2012.

[26] J. Gómez-Laguna, L. Carrasco, G. Ramis, J. J. Quereda, S. Gómez, and F. J. Pallarés, "Use of real-time and classic polymerase chain reaction assays for the diagnosis of porcine tuberculosis in formalin-fixed, paraffin-embedded tissues," Journal of Veterinary Diagnostic Investigation, vol. 22, no. 1, pp. 123-127, 2010.

[27] C. Richomme, M. L. Boschiroli, J. Hars, F. Casabianca, and C. Ducrot, "Bovine tuberculosis in livestock and wild boar on the Mediterranean Island, Corsica," Journal of Wildlife Diseases, vol. 46, no. 2, pp. 627-631, 2010.

[28] S. Zanetti, A. Bua, P. Molicotti et al., "Identification of mycobacterial infections in wild boars in Northern Sardinia, Italy," Acta Veterinaria Hungarica, vol. 56, no. 2, pp. 145-152, 2008.

[29] V. Di Marco, P. Mazzone, M. T. Capucchio et al., "Epidemiological significance of the domestic black pig (Sus scrofa) in maintenance of bovine tuberculosis in sicily," Journal of Clinical Microbiology, vol. 50, no. 4, pp. 1209-1218, 2012.

[30] M. A. Essey, R. L. Payne, E. M. Himes, and D. Luchsinger, "Bovine tuberculosis surveys of axis deer and feral swine on the Hawaiian island of Molokai," in Proceedings of the 85th Annual Meeting of the US Animal Health Association, pp. 538549, St Louis, Mo, USA, 1981.

[31] V. Meikle, M. V. Bianco, F. C. Blanco et al., "Evaluation of pathogenesis caused in Cattle and Guinea Pig by a Mycobacterium bovis strain isolated from Wild Boar," BMC Veterinary Research, vol. 7, p. 37, 2011.

[32] M. Boadella, C. Gortazar, P. Acevedo et al., "Six recommendations for improving monitoring of diseases shared with wildlife: examples regarding mycobacterial infections in Spain," European Journal of Wildlife Research, vol. 57, no. 4, pp. 697-706, 2011.

[33] V. Kaden, E. Lange, U. Fischer, and G. Strebelow, "Oral immunisation of wild boar against classical swine fever: evaluation of the first field study in Germany," Veterinary Microbiology, vol. 73, no. 2-3, pp. 239-252, 2000.

[34] V. Kaden, H. Heyne, H. Kiupel et al., "Oral immunisation of wild boar against classical swine fever: concluding analysis of the recent field trials in Germany," Berliner und Munchener Tierarztliche Wochenschrift, vol. 115, no. 5-6, pp. 179-185, 2002.

[35] V. Kaden and B. Lange, "Oral immunisation against classical swine fever (CSF): onset and duration of immunity," Veterinary Microbiology, vol. 82, no. 4, pp. 301-310, 2001.

[36] C. Ballesteros, C. Gortázar, M. Canales et al., "Evaluation of baits for oral vaccination of European wild boar piglets," Research in Veterinary Science, vol. 86, no. 3, pp. 388-393, 2009.

[37] C. Ballesteros, J. Vicente, R. Carrasco-García, R. Mateo, J. de la Fuente, and C. Gortázar, "Specificity and success of oral-bait delivery to Eurasian wild boar in Mediterranean woodland habitats," European Journal of Wildlife Research, vol. 57, no. 4, pp. 749-757, 2011. 
[38] C. Ballesteros, J. M. Garrido, J. Vicente et al., "First data on Eurasian wild boar response to oral immunization with BCG and challenge with a Mycobacterium bovis field strain," Vaccine, vol. 27, no. 48, pp. 6662-6668, 2009.

[39] B. D. Cowled, E. Gifford, M. Smith, L. Staples, and S. J. Lapidge, "Efficacy of manufactured PIGOUT baits for localised control of feral pigs in the semi-arid Queensland rangelands," Wildlife Research, vol. 33, no. 5, pp. 427-437, 2006.

[40] B. D. Cowled, S. J. Lapidge, M. Smith, and L. Staples, "Attractiveness of a novel omnivore bait, PIGOUT, to feral pigs (Sus scrofa) and assessment of risks of bait uptake by non-target species," Wildlife Research, vol. 33, no. 8, pp. 651660, 2006.

[41] T. A. Campbell, S. J. Lapidge, and D. B. Long, "Using baits to deliver pharmaceuticals to feral swine in Southern Texas," Wildlife Society Bulletin, vol. 34, no. 4, pp. 1184-1189, 2006.

[42] T. A. Campbell and D. B. Long, "Species-specific visitation and removal of baits for delivery of pharmaceuticals to feral swine," Journal of Wildlife Diseases, vol. 43, no. 3, pp. 485491, 2007.

[43] R. J. Delahay, G. J. Wilson, G. C. Smith, and C. L. Cheeseman, "Vaccinating badgers (Meles meles) against Mycobacterium bovis: the ecological considerations," Veterinary Journal, vol. 166, no. 1, pp. 43-51, 2003.

[44] L. A. L. Corner, E. Costello, D. O'Meara et al., "Oral vaccination of badgers (Meles meles) with BCG and protective immunity against endobronchial challenge with Mycobacterium bovis," Vaccine, vol. 28, no. 38, pp. 6265-6272, 2010.

[45] B. Brochier, M. F. Aubert, P. P. Pastoret et al., "Field use of a vaccinia-rabies recombinant vaccine for the control of sylvatic rabies in Europe and North America," Revue Scientifique et Technique, vol. 15, no. 3, pp. 947-970, 1996.

[46] S. Rossi, F. Pol, B. Forot et al., "Preventive vaccination contributes to control classical swine fever in wild boar (Sus scrofa sp.)," Veterinary Microbiology, vol. 142, no. 1-2, pp. 99$107,2010$.

[47] B. M. Buddle, D. N. Wedlock, M. Denis, H. M. Vordermeier, and R. G. Hewinson, "Update on vaccination of cattle and wildlife populations against tuberculosis," Veterinary Microbiology, vol. 151, no. 1-2, pp. 14-22, 2011.

[48] C. Ballesteros, J. M. de la Lastra, and J. de la Fuente, "Recent developments in oral bait vaccines for wildlife," Recent Patents on Drug Delivery \& Formulation, vol. 1, no. 3, pp. 230-235, 2007.

[49] A. Brauer, E. Lange, and V. Kaden, "Oral immunisation of wild boar against classical swine fever: uptake studies of new baits and investigations on the stability of lyophilised Cstrain vaccine," European Journal of Wildlife Research, vol. 52, no. 4, pp. 271-276, 2006.

[50] A. Vos, T. Selhorst, R. Schröder, and J. Mulder, "Feasibility of oral rabies vaccination campaigns of young foxes (Vulpes vulpes) against rabies in summer," European Journal of Wildlife Research, vol. 54, no. 4, pp. 763-766, 2008.

[51] F. E. Aldwell, D. L. Keen, N. A. Parlane, M. A. Skinner, G. W. De Lisle, and B. M. Buddle, "Oral vaccination with Mycobacterium bovis BCG in a lipid formulation induces resistance to pulmonary tuberculosis in brushtail possums," Vaccine, vol. 22, no. 1, pp. 70-76, 2003.

[52] M. L. Cross, R. J. Henderson, M. R. Lambeth, B. M. Buddle, and F. E. Aldwell, "Lipid-formulated bcg as an oralbait vaccine for tuberculosis: vaccine stability, efficacy, and palatability to brushtail possums (Trichosurus vulpecula) in
New Zealand," Journal of Wildlife Diseases, vol. 45, no. 3, pp. 754-765, 2009.

[53] D. M. Tompkins, D. S. L. Ramsey, M. L. Cross, F. E. Aldwell, G. W. De Lisle, and B. M. Buddle, "Oral vaccination reduces the incidence of tuberculosis in free-living brushtail possums," Proceedings of the Royal Society B, vol. 276, no. 1669, pp. 2987-2995, 2009.

[54] P. Nol, M. V. Palmer, W. R. Waters et al., "Efficacy of oral and parenteral routes of Mycobacterium bovis bacilli CalmetteGuerin vaccination against experimental bovine tuberculosis in white-tailed deer (Odocoileus virginianus): a feasibility study," Journal of Wildlife Diseases, vol. 44, no. 2, pp. 247-259, 2008.

[55] C. Ballesteros, J. Vicente, G. Morriss et al., "Acceptance and palatability for domestic and wildlife hosts of baits designed to deliver a tuberculosis vaccine to wild boar piglets," Preventive Veterinary Medicine, vol. 98, no. 2-3, pp. 198-203, 2011.

[56] T. L. Fry and M. R. Dunbar, "A review of biomarkers used for wildlife damage and disease management," in Proceedings of the 12th Wildlife Damage Management Conference, D. L. Nolte, W. M. Arjo, and D. H. Stalman, Eds., pp. 217-222, 2007.

[57] W. O. Fletcher, T. E. Creekmore, M. S. Smith, and V. F. Nettles, "A field trial to determine the feasibility of delivering oral vaccines to wild swine," Journal of Wildlife Diseases, vol. 26, no. 4, pp. 502-510, 1990.

[58] J. Mitchell, "The effectiveness of aerial baiting for control of feral pigs (Sus scrofa) in North Queensland," Wildlife Research, vol. 25, no. 3, pp. 297-303, 1998.

[59] P. J. S. Fleming, D. Choquenot, and R. J. Mason, "Aerial baiting of feral pigs (Sus scrofa) for the control of exotic disease in the semi-arid rangelands of New South Wales," Wildlife Research, vol. 27, no. 5, pp. 531-537, 2000.

[60] B. D. Cowled, S. J. Lapidge, M. L. Smith, and L. D. Staples, "Vaccination of feral pigs (Sus scrofa) using iophenoxic acid as a simulated vaccine," Australian Veterinary Journal, vol. 86, no. 1-2, pp. 50-55, 2008.

[61] G. Massei, A. Jones, T. Platt, and D. P. Cowan, "Iophenoxic acid as a long-term marker for wild boar," Journal of Wildlife Management, vol. 73, no. 3, pp. 458-461, 2009.

[62] C. Ballesteros, M. Sage, P. Fisher et al., "Iophenoxic acid as a bait marker for wild mammals: efficacy and safety considerations," Mammal Review. In press.

[63] C. Ballesteros, P. R. Camarero, C. Cristòfol et al., "Analysis by LC/ESI-MS of iophenoxic acid derivatives and evaluation as markers of oral baits to deliver pharmaceuticals to wildlife," Journal of Chromatography, vol. 878, no. 22, pp. 1997-2002, 2010.

[64] T. A. Campbell, D. B. Long, and G. Massei, "Efficacy of the Boar-Operated-System to deliver baits to feral swine," Preventive Veterinary Medicine, vol. 98, no. 4, pp. 243-249, 2011.

[65] D. B. Long, T. A. Campbell, and G. Massei, "Evaluation of feral swine-specific feeder systems," Rangelands, vol. 32, no. 2, pp. 8-13, 2010.

[66] G. Massei, J. Coats, R. Quy, K. Storer, and D. P. Cowan, “The boar-operated-system: a novel method to deliver baits to wild pigs," Journal of Wildlife Management, vol. 74, no. 2, pp. 333336, 2010.

[67] S. Lapidge, J. Wishart, L. Staples et al., "Development of a feral swine toxic bait (HOG-GONE) and bait hopper (HOGHOPPER) in Australia and the USA," in Proceedings of the Wildlife Damage Management Conference, vol. 14, 2011. 
[68] T. A. Campbell, M. J. Bodenchuk, J. D. Eisemann et al., "Efficacy of the HogHopper at Excluding Non-target Wildlife," in Proceedings of the Vertebrate Pest Conference, vol. 25, 2012.

[69] P. H. Obrien and B. S. Lukins, "Factors influencing the intake of sodium monofluoroacetate (Compound-1080) by freeranging feral Pigs," Australian Wildlife Research, vol. 15, no. 3, pp. 285-291, 1988.

[70] G. Saunders, B. Kay, and B. Parker, "Evaluation of a warfarin poisoning programme for feral pigs (Sus scrofa)," Australian Wildlife Research, vol. 17, no. 5, pp. 525-533, 1990.

[71] M. J. Brennan, "The tuberculosis vaccine challenge," Tuberculosis, vol. 85, no. 1-2, pp. 7-12, 2005.

[72] A. Calmette, La Vaccination Preventive Contre la Tuberculose per la BCG, Masson et cie, 1927.

[73] N. Ohara and T. Yamada, "Recombinant BCG vaccines," Vaccine, vol. 19, no. 30, pp. 4089-4098, 2001.

[74] C. Franco-Paredes, N. Rouphael, C. Del Rio, and J. I. SantosPreciado, "Vaccination strategies to prevent tuberculosis in the new millennium: from BCG to new vaccine candidates," International Journal of Infectious Diseases, vol. 10, no. 2, pp. 93-102, 2006.

[75] D. Murphy, L. A. L. Corner, and E. Gormley, "Adverse reactions to Mycobacterium bovis bacille Calmette-Guérin (BCG) vaccination against tuberculosis in humans, veterinary animals and wildlife species," Tuberculosis, vol. 88, no. 4, pp. 344-357, 2008.

[76] S. Lesellier, S. Palmer, D. J. Dalley et al., "The safety and immunogenicity of Bacillus Calmette-Guérin (BCG) vaccine in European badgers (Meles meles)," Veterinary Immunology and Immunopathology, vol. 112, no. 1-2, pp. 24-37, 2006.

[77] L. A. L. Corner, S. Norton, B. M. Buddle, and R. S. Morris, "The efficacy of bacille Calmette-Guérin vaccine in wild brushtail possums (Trichosurus vulpecula)," Research in Veterinary Science, vol. 73, no. 2, pp. 145-152, 2002.

[78] L. M. de Klerk, A. L. Michel, R. G. Bengis, N. P. J. Kriek, and J. Godfroid, "BCG vaccination failed to protect yearling African buffaloes (Syncerus caffer) against experimental intratonsilar challenge with Mycobacterium bovis," Veterinary Immunology and Immunopathology, vol. 137, no. 1-2, pp. 8492, 2010.

[79] J. F. T. Griffin, C. G. Mackintosh, L. Slobbe, A. J. Thomson, and G. S. Buchan, "Vaccine protocols to optimise the protective efficacy of BCG," Tubercle and Lung Disease, vol. 79, no. 3, pp. 135-143, 1999.

[80] T. Qureshi, R. E. Labes, M. L. Cross, J. F. T. Griffin, and C. G. Mackintosh, "Partial protection against oral challenge with Mycobacterium bovis in ferrets (Mustela furo) following oral vaccination with BCG," International Journal of Tuberculosis and Lung Disease, vol. 3, no. 11, pp. 1025-1033, 1999.

[81] M. A. Chambers, F. Rogers, R. J. Delahay et al., "Bacillus Calmette-Guérin vaccination reduces the severity and progression of tuberculosis in badgers," Proceedings of the Royal Society B, vol. 278, no. 1713, pp. 1913-1920, 2011.

[82] G. J. Wilson, S. P. Carter, and R. J. Delahay, "Advances and prospects for management of TB transmission between badgers and cattle," Veterinary Microbiology, vol. 151, no. 1-2, pp. 43-50, 2011.

[83] G. W. Comstock, "Field trials of tuberculosis vaccines: how could we have done them better?" Controlled Clinical Trials, vol. 15, no. 4, pp. 247-276, 1994.

[84] M. A. Skinner, D. N. Wedlock, and B. M. Buddle, "Vaccination of animals against Mycobacterium bovis," OIE Revue Scientifique et Technique, vol. 20, no. 1, pp. 112-132, 2001.
[85] R. G. Hewinson, H. M. Vordermeier, and B. M. Buddle, "Use of the bovine model of tuberculosis for the development of improved vaccines and diagnostics," Tuberculosis, vol. 83, no. 1-3, pp. 119-130, 2003.

[86] J. C. Hope and B. Villarreal-Ramos, "Bovine TB and the development of new vaccines," Comparative Immunology, Microbiology and Infectious Diseases, vol. 31, no. 2-3, pp. 77$100,2008$.

[87] P. Andersen and T. M. Doherty, "The success and failure of BCG-Implications for a novel tuberculosis vaccine," Nature Reviews Microbiology, vol. 3, no. 8, pp. 656-662, 2005.

[88] A. W. Olsen, L. Brandt, E. M. Agger, L. A. H. Van Pinxteren, and P. Andersen, "The influence of remaining live BCG organisms in vaccinated mice on the maintenance of immunity to tuberculosis," Scandinavian Journal of Immunology, vol. 60 , no. 3, pp. 273-277, 2004.

[89] T. Hawkridge and H. Mahomed, "Prospects for a new, safer and more effective TB vaccine," Paediatric Respiratory Reviews, vol. 12, no. 1, pp. 46-51, 2011.

[90] B. M. Buddle, G. W. De Lisle, A. Pfeffer, and F. E. Aldwell, "Immunological responses and protection against Mycobacterium bovis in calves vaccinated with a low dose of BCG," Vaccine, vol. 13, no. 12, pp. 1123-1130, 1995.

[91] F. E. Aldwell, M. L. Cross, C. E. Fitzpatrick, M. R. Lambeth, G. W. De Lisle, and B. M. Buddle, "Oral delivery of lipidencapsulated Mycobacterium bovis BCG extends survival of the bacillus in vivo and induces a long-term protective immune response against tuberculosis," Vaccine, vol. 24, no. 12, pp. 2071-2078, 2006.

[92] M. V. Palmer, T. C. Thacker, and W. R. Waters, "Vaccination of white-tailed deer (Odocoileus virginianus) with Mycobacterium bovis bacillus Calmette Guerín," Vaccine, vol. 25, no. 36, pp. 6589-6597, 2007.

[93] Tubeculosis Program PHS, "Experimental studies of vaccination, allergy, and immunity in tuberculosis. 3. Effect of killed vaccine," Bulletin of the World Health Organization, vol. 12, pp. 47-62, 1955.

[94] M. A. Chambers, D. C. Wright, J. Brisker et al., "A single dose of killed Mycobacterium bovis BCG in a novel class of adjuvant (Novasome) protects guinea pigs from lethal tuberculosis," Vaccine, vol. 22, no. 8, pp. 1063-1071, 2004.

[95] H. Zinsser, H. Ward, and F. Jennings, "The significance of bacterial allergy as a sign of resistance," The Journal of Immunology, vol. 10, no. 4, pp. 719-723, 1925.

[96] S. A. Petroff, A. Branch, and F. Jennings, "Resistance of animals sensitized with heat-killed Tubercle bacilli to a measured infecting dose," The Journal of Immunology, vol. 16, no. 3, pp. 233-257, 1929.

[97] B. Lange, R. Freund, and E. Jochimsen, "Über Versuche, bei Meerschweinchen durch Vorbehandlung mit abgetoteten Tuberkelbazillen Tuberkulinempfindlichkeit und Immunitat zu erzeugen. II. Mitteilung," Zeitschrift für Hygiene und Infektionskrankheiten, vol. 107, no. 2, pp. 426-435, 1927.

[98] W. Pagel, "Experiments on "dissociation" of allergic hypersensitiveness and immunity," The Journal of Pathology and Bacteriology, vol. 44, no. 3, pp. 643-659, 1937.

[99] S. A. Petroff and F. W. Stewart, "Immunological studies in tuberculosis. III. Concerning allergic reactions obtained in animals sensitized with killed tubercle bacilli," The Journal of Immunology, vol. 10, no. 4, pp. 677-717, 1925.

[100] A. Milzer, S. O. Levinson, and M. B. Lewis, "Immunization of mice with ultraviolet killed tuberculosis vaccines," Proceedings of the Society for Experimental Biology and Medicine. 
Society for Experimental Biology and Medicine, vol. 75, no. 3, pp. 733-736, 1950.

[101] R. J. Dubos, W. B. Schaefer, and C. H. Pierce, "Antituberculous immunity in mice vaccinated with killed tubercle bacilli," The Journal of Experimental Medicine, vol. 97, no. 2, pp. 221-233, 1953.

[102] M. Haile, U. Schröder, B. Hamasur et al., "Immunization with heat-killed Mycobacterium bovis bacille CalmetteGuerin (BCG) in Eurocine L3 adjuvant protects against tuberculosis," Vaccine, vol. 22, no. 11-12, pp. 1498-1508, 2004.

[103] M. A. Skinner, S. Yuan, R. Prestidge, D. Chuk, J. D. Watson, and P. L. J. Tan, "Immunization with heat-killed Mycobacterium vaccae stimulates CD8+ cytotoxic T cells specific for macrophages infected with Mycobacterium tuberculosis," Infection and Immunity, vol. 65, no. 11, pp. 4525-4530, 1997.

[104] G. Salvioli, A. Degli Esposti, and M. A. Dina, "Experimental tuberculosis in non-vaccinated dogs and in dogs vaccinated with living (BCG) and dead (AIP, VPS and VDS) bacilli," Acta Tuberculosea Scandinavica, vol. 28, no. 1-2, pp. 147-154, 1953.

[105] M. V. Palmer, D. L. Whipple, and S. C. Olsen, "Development of a model of natural infection with Mycobacterium bovis in white-tailed deer," Journal of Wildlife Diseases, vol. 35, no. 3, pp. 450-457, 1999.

[106] M. A. Skinner, D. L. Keen, N. A. Parlane, G. F. Yates, and B. M. Buddle, "Increased protection against bovine tuberculosis in the brushtail possum (Trichosurus vulpecula) when BCG is administered with killed Mycobacterium vaccae," Tuberculosis, vol. 82, no. 1, pp. 15-22, 2002.

[107] J. M. Garrido, I. A. Sevilla, B. Beltrán-Beck et al., "Protection against tuberculosis in eurasian wild boar vaccinated with heat-inactivated Mycobacterium bovis," PLoS ONE, vol. 6, no. 9, Article ID e24905, 2011.

[108] J. M. P. d. l. Lastra, R. C. Galindo, C. Gortázar, F. Ruiz-Fons, A. Aranaz, and J. de la Fuente, "Expression of immunoregulatory genes in peripheral blood mononuclear cells of European wild boar immunized with BCG," Veterinary Microbiology, vol. 134, no. 3-4, pp. 334-339, 2009.

[109] J. M. Garrido, J. Vicente, R. Carrasco-García et al., "Experimental infection of Eurasian wild boar with Mycobacterium avium subsp. avium," Veterinary Microbiology, vol. 144, no. 1-2, pp. 240-245, 2010.

[110] O. Aurtenetxe, M. Barral, J. Vicente, J. De La Fuente, C. Gortázar, and R. A. Juste, "Development and validation of an enzyme-linked immunosorbent assay for antibodies against Mycobacterium bovis in European wild boar," BMC Veterinary Research, vol. 4, article 43, 2008.

[111] M. Boadella, K. Lyashchenko, R. Greenwald et al., "Serologic tests for detecting antibodies against Mycobacterium bovis and Mycobacterium avium subspecies paratuberculosis in Eurasian wild boar (Sus scrofa scrofa)," Journal of Veterinary Diagnostic Investigation, vol. 23, no. 1, pp. 77-83, 2011.

[112] R. C. Galindo, P. Ayoubi, V. Naranjo, C. Gortazar, K. M. Kocan, and J. de la Fuente, "Gene expression profiles of European wild boar naturally infected with Mycobacterium bovis," Veterinary Immunology and Immunopathology, vol. 129, no. 1-2, pp. 119-125, 2009.

[113] V. Naranjo, P. Ayoubi, J. Vicente et al., "Characterization of selected genes upregulated in non-tuberculous European wild boar as possible correlates of resistance to Mycobacterium bovis infection," Veterinary Microbiology, vol. 116, no. 1-3, pp. 224-231, 2006.
[114] V. Naranjo, U. Höfle, J. Vicente et al., "Genes differentially expressed in oropharyngeal tonsils and mandibular lymph nodes of tuberculous and nontuberculous European wild boars naturally exposed to Mycobacterium bovis," FEMS Immunology and Medical Microbiology, vol. 46, no. 2, pp. 298-312, 2006.

[115] V. Naranjo, M. Villar, M. P. Martín-Hernando et al., "Proteomic and transcriptomic analyses of differential stress/ inflammatory responses in mandibular lymph nodes and oropharyngeal tonsils of European wild boars naturally infected with Mycobacterium bovis," Proteomics, vol. 7, no. 2, pp. 220-231, 2007.

[116] V. Naranjo, K. Acevedo-Whitehouse, J. Vicente, C. Gortazar, and J. De La Fuente, "Influence of methylmalonyl-CoA mutase alleles on resistance to bovine tuberculosis in the European wild boar (Sus scrofa)," Animal Genetics, vol. 39, no. 3, pp. 316-320, 2008.

[117] J. de la Fuente, C. Gortazar, J. Vicente, and M. Villar, "Host expression of methylmalonyl-CoA mutase and tuberculosis: a missing link?" Medical Hypotheses, vol. 76, no. 3, pp. 361364, 2011.

[118] M. A. Velasco-Velázquez, D. Barrera, A. González-Arenas, C. Rosales, and J. Agramonte-Hevia, "Macrophage-Mycobacterium tuberculosis interactions: role of complement receptor 3," Microbial Pathogenesis, vol. 35, no. 3, pp. 125131, 2003.

[119] J. S. Ferguson, J. J. Weis, J. L. Martin, and L. S. Schlesinger, "Complement protein C3 binding to Mycobacterium tuberculosis is initiated by the classical pathway in human bronchoalveolar lavage fluid," Infection and Immunity, vol. 72, no. 5, pp. 2564-2573, 2004.

[120] F. Luelmo, "BCG vaccination," American Review of Respiratory Disease, vol. 125, no. 3, pp. 70-72, 1982.

[121] A. Raja, "Immunology of tuberculosis," Indian Journal of Medical Research, vol. 120, no. 4, pp. 213-232, 2004.

[122] V. Naranjo, C. Gortazar, M. Villar, and J. de la Fuente, "Comparative genomics and proteomics to study tissuespecific response and function in natural Mycobacterium bovis infections," Animal health research reviews / Conference of Research Workers in Animal Diseases, vol. 8, no. 1, pp. 8188, 2007.

[123] G. T. Seah and G. A. W. Rook, "High levels of mRNA encoding IL-4 in unstimulated peripheral blood mononuclear cells from tuberculosis patients revealed by quantitative nested reverse transcriptase-polymerase chain reaction; correlations with serum IgE levels," Scandinavian Journal of Infectious Diseases, vol. 33, no. 2, pp. 106-109, 2001.

[124] M. V. Palmer, T. C. Thacker, and W. R. Waters, "Vaccination with Mycobacterium bovis BCG strains Danish and Pasteur in white-tailed deer (Odocoileus virginianus) experimentally challenged with Mycobacterium bovis," Zoonoses and Public Health, vol. 56, no. 5, pp. 243-251, 2009.

[125] D. N. Wedlock, F. E. Aldwell, D. Keen, M. A. Skinner, and B. M. Buddle, "Oral vaccination of brushtail possums (Trichosurus vulpecula) with BCG: immune responses, persistence of BCG in lymphoid organs and excretion in faeces," New Zealand Veterinary Journal, vol. 53, no. 5, pp. 301-306, 2005.

[126] W. R. Waters, M. V. Palmer, B. M. Buddle, and H. M. Vordermeier, "Bovine tuberculosis vaccine research: historical perspectives and recent advances," Vaccine, vol. 30, no. 16, pp. 2611-2622, 2012. 

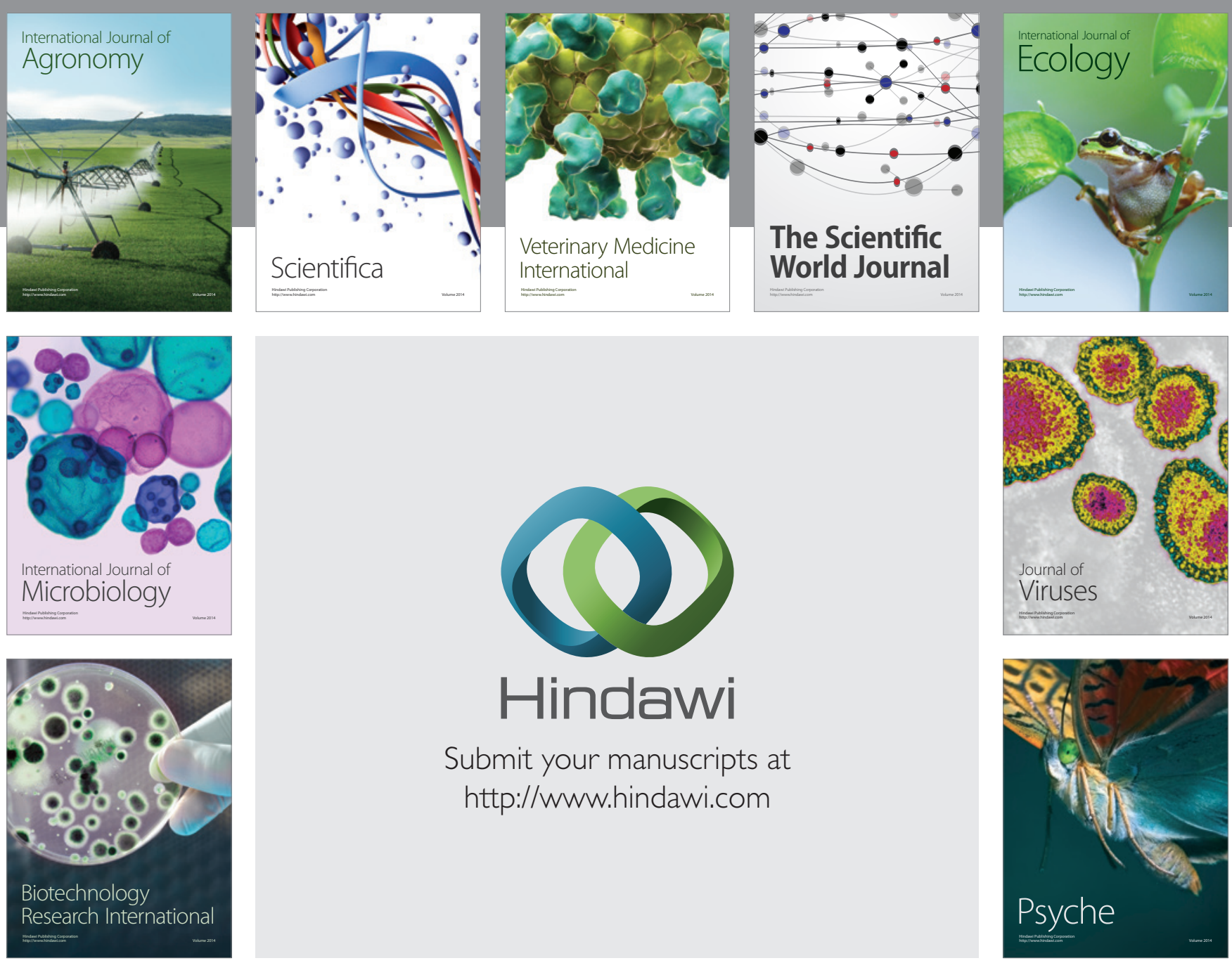

Submit your manuscripts at

http://www.hindawi.com
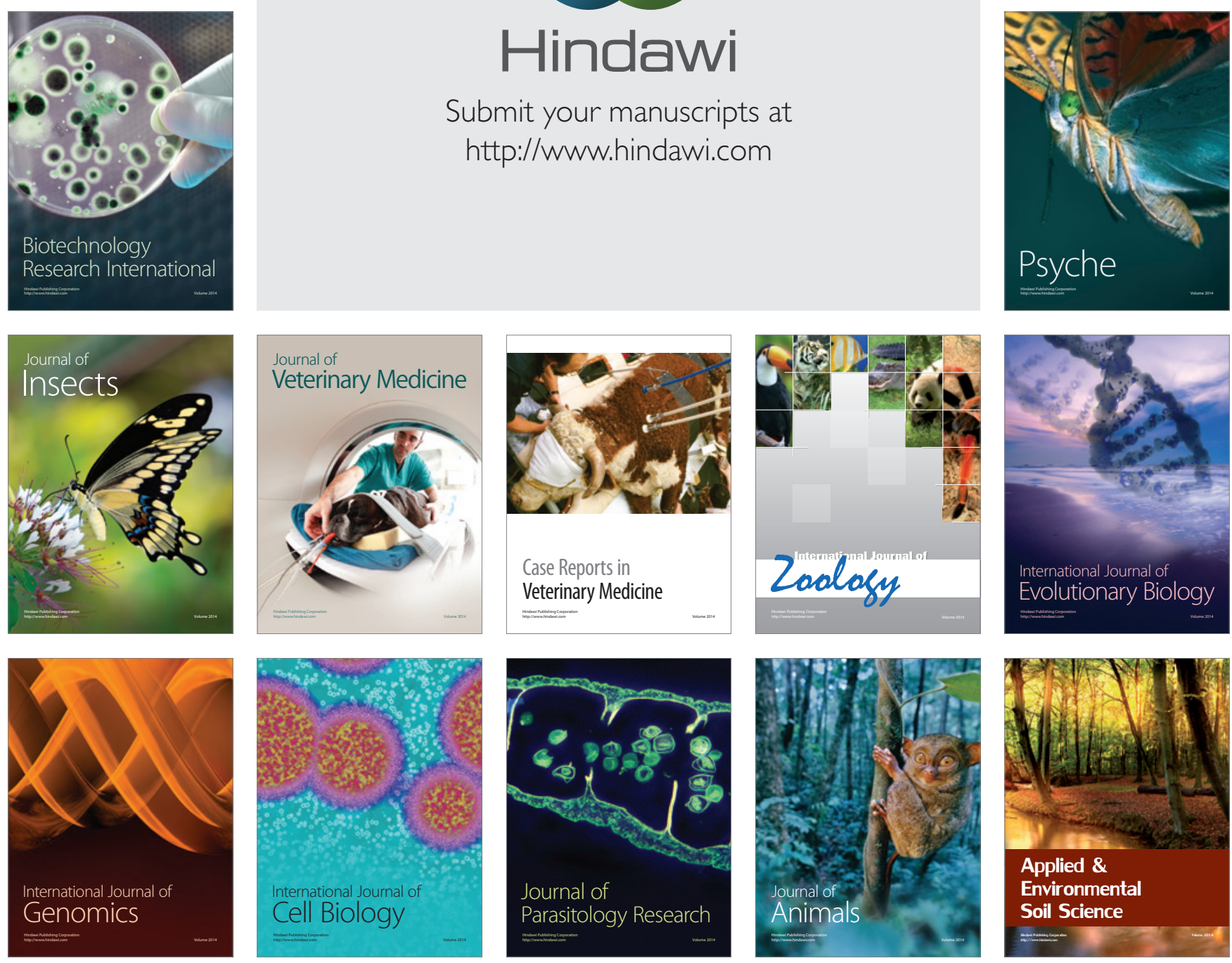